\section{Prácticas sociales genocidas: La transformación de la educación escolar chilena entre los años 1979 y 1990*}

Genocidal Social Practices: The transformation of Chilean school education between 1979 and 1990

\section{Mauricio Weibel B.*}

\section{Resumen}

Este artículo analiza la existencia de prácticas sociales genocidas en la educación escolar chilena, como parte de un proceso general de transformaciones económico sociales impulsadas por la dictadura cívico militar del

\footnotetext{
* Este artículo forma parte de la tesis doctoral "Prácticas sociales genocidas en países miembros del Plan Cóndor como Argentina, Chile, Paraguay y Uruguay: La transformación de la educación secundaria chilena entre los años 1979 y 1990", realizada en la Universidad de Santiago de Chile.

** Institución: Universidad de Santiago de Chile / Dirección: Jesús 755, La Reina, Santiago de Chile / Zip Code: 7870034 / Correo lectrónico: weibel.mauricio@gmail.com
}

general Augusto Pinochet (1973-1990). La originalidad de la investigación reside en que gracias al hallazgo de un corpus de miles de oficios reservados es posible observar cómo un régimen autoritario operó en su intimidad institucional para imponer cambios en las relaciones sociales.

Palabras clave: Archivos secretos, estudios genocidas, educación, transformaciones político sociales.

\begin{abstract}
This article analyzes the existence of genocidal social practices in Chilean school education, as part of a general process of social economic transformation driven by the civil-military dictatorship of General Augusto Pinochet (1973- 1990). The originality of the research is that, thanks to a corpus of thousands of secret archives, it makes it possible to see how an authoritarian regime operated in its institutional intimacy to impose changes in social relations.
\end{abstract}

Key words: Secret archives, genocide studies, education, political and social transformation. 


\section{Introducción}

El hallazgo y revisión de sesenta mil fojas de archivos secretos de la dictadura militar chilena (1973-1990) sobre educación en las bóvedas del Archivo Nacional en $2013^{1}$ permitió observar en su cotidianeidad el despliegue de lo que teóricamente diversos autores latinoamericanos han definido como prácticas sociales genocidas.

Es decir, el uso de una serie de tecnologías de poder dispuestas selectivamente desde el Estado, para facilitar o provocar una transformación de las relaciones entre Estado, economía y sociedad.

En este punto, es importante subrayar que esta perspectiva de análisis se enmarca en los debates sobre los «politicidios» acontecidos en el siglo XX en Europa, Asia o África, concepto desarrollado por autores como Bárbara Harff y Ted Gurr (1988, 329-371) y, para los casos de América latina, por las contribuciones de Daniel Feierstein (2007), quien acuñó el concepto de «genocidio reorganizador».

Los primeros subrayan que, a diferencia de la concepción clásica de genocidio (como el exterminio masivo de una etnia o pueblo), el «politicidio» apunta a «la promoción y ejecución de políticas por parte del Estado o de agentes del mismo, las cuales resultan en la muerte de un número sustancial de personas de un grupo» (Feierstein, 2007: 60), en función de su oposición política a un régimen autoritario, es decir a un proyecto político.

Estos materiales son documentos de libre acceso y no refieren a situaciones personales que denigren a personas, sino esencialmente refieren a resoluciones político represivas adoptadas por el régimen en el sector de Educación entre los años 1979 y 1990, como parte de su plan de transformación de la educación.
Feierstein define el genocidio como una práctica social. Es decir, como «aquella tecnología de podercuyo objetivo radica en la destrucción de las relaciones sociales de autonomía, cooperación e identidad de una sociedad, por medio del aniquilamiento de una fracción relevante de dicha sociedad (ya sea por su número o por los efectos de sus prácticas)» (2007:66).

Ergo, el uso del terror y el aniquilamiento de un sector social tiene por objetivo estratégico establecer nuevas relaciones sociales y nuevos modelos identitarios.

Eso es lo que sucedió en Chile bajo el régimen militar. En efecto, los documentos revisados, que abarcan desde las directrices de contratación de personal hasta las estrategias para el desarrollo de las relaciones internacionales del Ministerio de Educación chileno, facilitan observar la institucionalización de un conjunto de prácticas sociales que legitimaron tanto una campaña de exterminio como de control cotidiano, las cuales fueron funcionales para las transformaciones en la educación escolar chilena al día de hoy.

El estudio de estos documentos secretos de la dictadura cívico militar chilena permite ampliar las perspectivas teóricas existentes, al constatar como el terrorismo institucional también se sirvió del Misterio de Educación para avanzar en la destrucción de grupos sociales y/o políticos.

Efectivamente, el incorporar en los análisis los conceptos de «prácticas sociales genocidas» y de "genocidio reorganizador», faculta observar como las acciones de esta dependencia gubernamental contribuyó a la realización de dispositivos simbólicos (estigmatización, negación de la identidad, inversión de la culpabilidad) y materiales 
(control, coerción, delación, vigilancia,) que fueron imprescindibles para establecer nuevos sentidos y nuevas relaciones de poder al interior de los establecimientos educacionales $\mathrm{y}$, por extensión, en la sociedad.

Ciertamente, las prácticas sociales genocidas operan en un momento de pre producción que es la construcción de otredades negativas, un momento de producción que implica el exterminio, primero, y la transformación social, después; y un momento de post producción que es el de la validación simbólica de la transformación.

La revisión de los oficios secretos y reservados de la dictadura militar encontrados en el Archivo Nacional permitió observar, adicionalmente, que estos momentos en realidad se entrecruzan y se requieren mutua y permanentemente, pero que también están limitados por las acciones de resistencia y memoria, aspecto que desarrollamos con más profundidad en los capítulos siguientes.

En términos esquemáticos, las prácticas sociales genocidas que operaron al interior de la educación escolar chilena fueron básicamente los siguientes: i) Construcción de identidad y otredades negativas, ii) Articulación de Estado y políticas públicas con perspectiva de seguridad, iii) Vigilancia monocultural con perspectiva de seguridad de la práctica docente, iv) Contención ofensiva y defensiva de actores autónomos (Iglesia) y v) Cristalización simbólica y constitucional de la transformación.

En cada uno de estos procesos, fue posible identificar una variedad de dispositivos explicitados en los propios documentos revisados, como se detalla en el capítulo 2.
Es importante subrayar que, pese a las resistencias sociales, el despliegue global de estos procesos permitió -tras el fin de la dictadura- consolidar una transformación neoliberal que modificó estructuralmente las relaciones sociales en Chile, incluida la educación que fue convertida en un espacio de creciente segregación.

Es decir, de mantención de la propia transformación neoliberal. Este último proceso, tema que por ahora sólo enunciamos exploratoriamente, perduró en democracia a través de la persistencia de las prácticas sociales genocidas a través de modelos alternos de coerción: criminalización de la protesta social, la desmovilización de los actores sociales, la segregación socio-territorial de la población y la concentración de los medios de comunicación, entre otros.

El genocidio reorganizador acaecido en Chile no sólo constituyó la desarticulación y el exterminio físico de un grupo, si no que esencialmente representó la transformación de una sociedad a través de mecanismos sociales e institucionales coercitivos que buscan construir nuevas relaciones y equilibrios entre sociedad, economía y política.

En su forma más radical, supuso la suplantación de una cultura por otra. Este es el punto central. Por cierto, no todos los genocidios ni todas las prácticas sociales que los apuntalan derivan en transformaciones de las relaciones entre Estado, economía y sociedad. Tampoco todas estas transformaciones se naturalizan.

Por ello resulta tan interesante estudiar -a la luz de estos documentos- la transformación acaecida en la educación escolar chilena, pues 
las prácticas sociales genocidas desplegadas por la dictadura del general Augusto Pinochet (1973-1990) derivaron en la naturalización de dispositivos de poder y de una nueva concepción de educación a lo largo de estas últimas tres décadas, asumida como válida incluso por amplios sectores de quienes lucharon contra la misma dictadura cívico militar.

Validando la pertinencia de este estudio, es necesario resaltar que lo sucedido en Chile no fue un proceso aislado en América latina. $\mathrm{Ni}$ un accidente histórico dentro del proceso global de estandarización de la violencia política estatal.

Bajo el influjo de la Doctrina de Seguridad Nacional, la región y muy especialmente su Cono Sur fueron escenarios de persistentes y coordinadas prácticas sociales genocidas en la segunda mitad del siglo XX, cuyo objetivo fue instaurar sociedades atomizadas socialmente, despolitizadas en lo político y de corte neoliberal en lo económico.

Esto se expresó en transformaciones estructurales en el mercado laboral, la seguridad social y la segregación socioterritorial, entre otra variedad de dimensiones, las que con distintas profundidades persistieron naturalizadas en las democracias que advinieron tras las dictaduras militares de la segunda mitad del siglo XX.

Los miles de oficios secretos de la dictadura militar chilena analizados en esta investigación ${ }^{2}$ otorgan en ese sentido un amplio conocimiento de cómo fue construida diariamente la

\footnotetext{
Estos oficios, aunque son hoy de libre acceso fueron encontrados y sistematizados por primera vez en el marco de la presente investigación en las bóvedas del Archivo Nacional. Previamente se desconocía su existencia, debido principalmente a la creencia de que la dictadura cívico militar había destruido toda su documentación más sensible.
}

transformación de la educación escolar en este país, a través de prácticas institucionales y sociales que implicaron una ocupación cívico militar del sistema educativo, con una perspectiva tanto monocultural como de seguridad que supuso incluso una coordinación político represiva diaria y desconocida entre el Ministerio de Educación y la CNI (policía secreta), como aspecto esencial de la propia transformación impulsada por el régimen en sus niveles macro, meso y microsocial.

El período de estudio escogido coincide tanto con el auge y declive de las coordinaciones del Plan Cóndor como con el proceso institucional de municipalización de la educación pública chilena, así como con el auge, desarrollo y declive de la movilización en los colegios de este país.

Es coincidentemente el momento en que la dictadura chilena despliega otra serie de transformaciones, una vez descabezadas las primeras resistencias políticas al régimen encabezado por el general Augusto Pinochet en la década de 1970.

En el despliegue de este análisis se plantea en el apartado un breve debate sobre la evolución, límites y oscuridades de los conceptos de genocidio y de prácticas sociales genocidas, entrelazado con el proceso de estandarización de la violencia política estatal, así como una necesaria discusión sobre los modelos coercitivos y su despliegue general en la ocupación cívico-militar del Estado chileno, ocurrida tras el golpe militar de 1973.

En el apartado 2, identificamos los procesos y dispositivos que constituyeron las prácticas sociales genocidas en la educación chilena, incluida la naturalización de sus transformaciones. 
En las «Conclusiones», se plantean una serie de hallazgos e interrogantes que quedan abiertas, en especial sobre los mecanismos de naturalización de la transformación genocida.

\section{Apuntes para un debate civilizatorio}

En estas líneas, la idea es trazar algunas preocupaciones y perspectivas que enmarcaron la revisión de los miles de archivos secretos de la dictadura cívico-militar chilena.

No es un debate acabado sobre el totalitarismo, puesnoes elfoco de este texto, sino simplemente compartir un horizonte de sentido en el cual encuadrar el debate sobre las prácticas sociales genocidas en el proceso de transformación de la educación escolar chilena.

Quizá lo central es comprender que el problema de la violencia represiva estatal es antes que nada un problema civilizatorio, como plantea Enzo Traverso (2001).

De hecho, en tanto práctica social e histórica, los genocidios han existido por siglos, pero sus tecnologías y despliegues han variado.

El genocidio armenio, del cual se cumplieron cien años en 2015, es considerado el primero de la modernidad por la acción directa del Estado en él.

Estos procesos, ya fuera en Armenia, Camboya, Chile o Timor Oriental, tuvieron como característica distintiva el uso de tecnologías de poder estatales que buscaron mediante el exterminio y el terror provocar cambios estructurales en las relaciones sociales. Esto es central.
El concepto de genocidio surge como un neologismo acuñado por Raphael Lemkin (1944), el cual a lo largo de los decenios siguientes concitó consensos y divergencias en torno a su concepción jurídica y teórica.

Los horrores de la II Guerra Mundial, entre ellos la Shoah, no impidieron que inicialmente los gobiernos redujeran el concepto de genocidio a eliminaciones étnicas, descartando sus dimensiones políticas, sociales y culturales, por ejemplo.

Esto generó una serie de divergencias y debates sobre la intencionalidad del genocidio, el carácter de los grupos incluidos (étnicos, políticos, sexuales) y el grado total o parcial del exterminio. Surgieron perspectivas como las de Frank Chalk y Kurt Jonassohn (1990), de Israel Charny (2000) y de Vahakn Dadrian (2003), entre otros autores, quienes coincidieron en que el genocidio es la destrucción intencionada de un colectivo por parte del Estado.

No obstante, divergieron respecto de la amplitud y alcances (objetivos) de ese exterminio. Debido a estas diferencias, autores como Feierstein (2007) caracterizan estos procesos históricos como prácticas sociales genocidas, las que para su despliegue requieren determinados «modos de entrenamiento, perfeccionamiento, legitimización y consenso» (2007: 35).

Por ejemplo, las transformaciones neoliberales a las que fue sometida la educación chilena durante la dictadura cívico-militar corresponden a este tipo de prácticas sociales.

De hecho, sus consecuencias (objetivos) no fueron otros si no que modificar las relaciones sociales en el sistema educativo y, por tanto, en 
la sociedad en general. Es decir, las relaciones de poder.

En esta perspectiva, es posible afirmar que las prácticas sociales genocidas no concluyen con el aniquilamiento de determinados grupos poblacionales, sino que prosiguen al apuntalar y preservar el proceso de reorganización social, incluyendo para ello mecanismos de realización simbólica.

Estas transformaciones, según Feierstein (2007) implican una redistribución de la riqueza y el poder. Eventualmente, la cristalización de un armisticio constitucional y la imposición de cambios estructurales, como sucedió en Chile.

Estas prácticas es posible desarrollarlas, si es que ocurre previamente una transformación de la identidad y la alteridad en las sociedades donde estas ocurren.

«Las prácticas sociales genocidas (PSG) requieren de un momento conceptual inicial», el que Feierstein (2007) denomina «la construcción de otredades negativas». Se trata de una reducción de las identidades multiculturales que pueden existir en un Estado, a través de la deshumanización del semejante, como un paso previo a la normalización identitaria

\section{Estandarización global de las PSG}

La violencia política desplegada por los Estados latinoamericanos en la segunda mitad del siglo XX fue producto de un proceso de estandarización de prácticas sociales genocidas, desplegado globalmente en el marco de las guerras coloniales surgidas tras el fin de la II Guerra Mundial y la contención de luchas político sociales en diversos países (Salazar, 2012).

En diversos continentes la represión y la defensa de regímenes que ejecutaban transformaciones estructurales a través de estos métodos supuso convertir a los Estados en organizaciones que desplegaron acciones político represivas permanentes.

Este proceso estuvo ligado además a la idea de las potencias, en especial Francia y Estados Unidos, de que era aceptable o incluso legal desplegar este tipo de intervenciones a gran escala (Weiner, 2008).

Paralelamente, en la Guerra Fría, el enfrentamiento en operaciones abiertas y clandestinas entre el mundo capitalista y el bloque socialista, posterior al fin de la II Guerra Mundial en 1945, marcó transversalmente la ideología y sentido de los cuerpos militares latinoamericanos y su accionar político en la región.

Entre 1947 y 1949, emergieron el Tratado Interamericano de Asistencia Recíproca (TIAR) y el Tratado del Atlántico Norte en Europa, como estrategias para garantizar la influencia de Washington en zonas clave para su acceso a materias primas y tecnología, respectivamente.

Luego vinieron tres hechos clave que construyeron parte importante de la base ideológica de las fuerzas armadas latinoamericanas y chilenas, sustentando las políticas represivas y su estandarización.

Primero, la creación en Panamá, en 1946, de la Latin-American Ground School, precursora de la Escuela de las Américas, la institución 
que formó a miles de oficiales y represores que operaron desde 1960 a 1990 en el continente, entre ellos Manuel Contreras, primer director de la DINA y alumno de Pinochet en la Academia de Guerra (Weibel, 2012).

Segundo, la apertura de la Escuela Superior de Guerra en Brasil, país donde fue consolidada la Doctrina de Seguridad Nacional y su tesis del "enemigo interno", a partir de la dictadura militar instaurada en 1964, después del derrocamiento del presidente Joao Goulart.

Finalmente, el exitoso y mencionado descabezamiento del gobierno reformista guatemalteco de Arbenz, a través de la misión "PB Success", lo que validó tempranamente en Washington la eficacia de las operaciones encubiertas de la CIA en la región.

La derrota francesa en Vietnam en la batalla de Dien Bien Phu en 1954 y el triunfo de la Revolución Cubana en 1959, ratificaron paralelamente en las academias militares de Occidente la necesidad de impulsar el adiestramiento en estrategias contra insurgentes.

El objetivo de este esfuerzo fue frenar el avance comunista, confundido con cualquier reclamo social o guerra de liberación nacional.

La detallada construcción de fichas con antecedentes de personas, la estandarización de los enemigos internos, los métodos de exterminio y los manuales represivos tuvieron esos orígenes ${ }^{3}$. No fue azar. No fue simple

Este artículo forma parte de la tesis doctoral "Prácticas sociales genocidas en países miembros del Plan Cóndor como Argentina, Chile, Paraguay y Uruguay: La transformación de la educación secundaria chilena entre los años 1979 y 1990", realizada en la Universidad de Santiago de Chile. banalidad del mal espontánea o inconsciente. Hubo un derrotero históricamente situado en el marco de las guerras coloniales y la Guerra Fría, además de la supremacía geopolítica de Estados Unidos en América latina.

La lucha contrainsurgente y la necesidad de transformar neoliberalmente las sociedades fue convertida en una actividad central del Estado y los cuerpos represivos tuvieron, por tanto, un papel siempre político (Weibel, 2012).

Todo ello, como requisito, para instalar una contrarrevolución neoliberal, imposible de llevar adelante en una democracia representativa (Alvarez, 2008).

El horizonte de sentido de este proceso fue sin duda la Doctrina de Seguridad Nacional asumida como cuerpo ideológico por las fuerzas armadas y de orden latinoamericanas en la segunda mitad del siglo XX.

Esta doctrina definió la existencia de «enemigos internos», asociados a los movimientos sociales y revolucionarios, al tiempo que formalizó el concepto de "guerra de baja intensidad» como espacio de operación. Es decir, justificó ideológicamente la ocupación cívico-militar de los Estados y el espacio público en A. latina, a través de prácticas de violencia política.

\footnotetext{
** Institución: Universidad de Santiago de Chile / Dirección: Jesús 755, La Reina, Santiago de Chile / Zip Code: 7870034 / Correo lectrónico: weibel.mauricio@gmail.com Esta afirmación se desprende de la revisión del «Manual de Operaciones Secretas de la DINA", encontrado, revisado y publicado por el autor de este artículo.
} 


\subsection{Los modelos del horror y de la coerción}

Este proceso de estandarización global de la violencia política no es por tanto un accidente histórico, si no que puede y debe ser interpretado teóricamente además desde la ciencia política.

Como explica Policzer, "desde Hobbes a Weber, la coerción define nuestras instituciones públicas» (Policzer, 2014), a través de diversos modelos que abarcan desde los países que viven bajo regímenes democráticos hasta los sometidos al totalitarismo, sea este político o religioso.

La coerción también es una dimensión de la acción política de organizaciones no estatales que alcanzan en algunas circunstancias determinados niveles de dominios territoriales, como movimientos guerrilleros, organizaciones terroristas o carteles de las drogas (Policzer, 2006).

En este punto importa comprender, como plantea Tilly (2000), que el Estado hace la guerra y que la guerra hace al Estado. Es decir, el despliegue de distintos niveles de coerción requiere necesariamente una transformación del propio Estado, lo que supone diferentes esfuerzos y recursos.

En el caso chileno esto ocurrió por medio de un esfuerzo cívico-militar indispensable para el despliegue de una práctica social genocida, cuyo objetivo fue posibilitar una profunda transformación neoliberal en las relaciones sociales.

La coerción y su institucionalidad son por tanto actos eminentemente políticos. Parafraseando a von Clausewitz, y su famosa frase sobre la guerra, la coerción es la continuación de la política por otros medios.
Lo anterior supone que la organización y despliegue de la coerción son también procesos políticos, que implican definir desde los ámbitos de acción de los equipos (agencia) coercitivos hasta sus modos de organización y lo que Policzer (2014) llama mecanismos de monitorización (control) interno y externo.

¿Cuánto influyen la cultura y la historia oficial, en tanto ideología, en la formación de estos modos de coerción? ¿De qué forma los modelos de organización de la coerción influyen además en la profundidad y alcance de las violaciones a los derechos humanos? Por ahora estas interrogantes están abiertas.

No obstante, estas prevenciones, es posible postular la existencia de cuatro modelos de organización de la coerción, los que suponen diversas consecuencias políticas y administrativas.

Un primer tipo es la coerción burocrática, característica por ejemplo de la Stasi en la República Democrática Alemana (RDA). Este tipo de coerción supone altos niveles de monitorización (control) interno, pero bajo niveles de monitorización externa. Es decir, una escasa tolerancia a la oposición. Por ello, este es un tipo de coerción característico de regímenes totalitarios. Implica un alto control del gobernante sobre la agencia coercitiva, la que actúa con alta unidad y consistencia. Asimismo, supone altos niveles de información y de redes que la generen.

Un segundo modelo es el de la coerción ciega, más característica por ejemplo del proceso de dictadura de los años 1970 y 1980 en Argentina. Supone que no existen limitaciones al poder y sus consecuencias mortales, por un lado, 
pero por otro implica bajos niveles internos de control e información, dada la autonomía de los cuerpos represivos.

La coerción escondida, con baja monitorización interna y alta monitorización externa, es más propia de los regímenes democráticos, al igual que la coerción transparente que tiene altos niveles de monitorización interna y externa.

Probablemente, los procesos históricos mostrarán matices. Es decir, un mismo régimen puede transitar por varios modelos, según sus posibilidades y objetivos.

En el Cono Sur estos modelos fueron de hecho sometidos a una serie de innovaciones y ampliaciones, las que estuvieron enmarcadas en procesos regionales y globales históricamente situados, como el auge y declive de la Guerra Fría además de las guerras coloniales, entre otros.

\section{Coerción y ocupación cívico-militar del Estado en Chile}

En el caso de Chile, la coerción operó estructurada bajo un modelo que se puede definir como burocrático global.

Es decir, como un despliegue político represivo del Estado, en el que participaron coordinada y activamente civiles y militares en espacios de macro, meso y micropolítica, según se desprende de los miles de oficios revisados para la construcción de este artículo.

Esta coerción burocrática global, expresada en dispositivos de control, mecanismos de administración y un Plan de Guerra Interno que incluyó a los ministerios, fue respaldada por la construcción de dos anillos de seguridad externos, como se ha enunciado tácitamente.

El primero de esos anillos, en las lógicas de la Guerra Fría y la Doctrina de Seguridad, fue el analizado Plan Cóndor, creado en noviembre de 1975 en Santiago de Chile con la participación de las policías secretas de Argentina, Bolivia, Brasil, Chile, Paraguay y Uruguay.

El segundo fue el Plan de Guerra Exterior, el que esencialmente fue una operación de información y guerra sicológica contra colectivos chilenos o progresistas en todo el mundo.

Las coordinaciones partieron desde septiembre de 1973, pero es a partir de 1975 que el poder de la DINA y su capacidad para coordinar a ministerios y reparticiones, creció con el apoyo del general Pinochet (Weibel, 2012).

Un primer paso ocurrió el 20 de febrero de 1975 cuando Pinochet otorgó poder absoluto a la DINA para revisar la contratación de todos los funcionarios públicos.

La medida, que perduró hasta el final del régimen, fue aplicada para evitar que ningún opositor ingresara a la administración pública.

La decisión, que fue pormenorizada en años sucesivos, fue firmada por el ministro del Interior, el general Raúl Benavides, en la Circular Reservada 35 F-151: «Su Excelencia -informó Benavides a todos los ministerios- ha dispuesto que a partir de esta fecha ningún funcionario público sea contratado sin que previamente se adjunte a los antecedentes un informe DINA respecto a las actividades que el interesado pudo haber realizado». 
En 1979, la CNI escaló otro peldaño institucional. Su director, Odlanier Mena, informó a los ministerios que la policía secreta no solo emitiría fichas sobre los funcionarios, sino que además requería tener el organigrama directivo de los ministerios, con una explicación de todos los movimientos de funcionarios.

Pero las relaciones institucionales de la DINA y la CNI con los ministros y sus subalternos fueron mucho más hondas, de estrecha colaboración político estratégica.

Hubo traspaso mutuo de información obtenida por infiltrados que reportaron a los ministerios o la policía secreta indistintamente.

Existieron también operaciones conjuntas, distribución de análisis e intercambio de opiniones políticas ante el escenario externo. Todo estrictamente membreteado como reservado o confidencial.

De esta forma, las estrategias más íntimas de la dictadura transitaron sin problemas por los escritorios de las autoridades bajo la coordinación de la CNI, incluidas las operaciones de inteligencia asociadas a la entrega del poder hacia 1990.

Las golpizas y las aplicaciones de electricidad en los campos de exterminio convivieron con las discusiones políticas sobre cuáles eran los límites de las políticas represivas. «¿Cuántos presos tener? ¿Cómo desvirtuar las acusaciones por violaciones a los derechos humanos? ¿Qué hacer con los opositores? ¿Expulsarlos del país o relegarlos a los pueblos cordilleranos?» (Weibel, 2012; 77).

Todo este modelo coercitivo, y sus dispositivos, operaron sobre la educación e incluso los colegios y sus salas de clases.

\section{Cartografía de una transformación ${ }^{4}$}

La primera revelación masiva de documentos reservados y secretos de la dictadura militar chilena ocurrió el año 2012 en el marco de una investigación periodística ${ }^{5}$.

Estos oficios correspondían a comunicaciones formales entre la policía secreta, los ministerios del área política, la Cancillería, la cartera de Defensa y la Junta Militar, principalmente.

Cada uno de estos memorandos tenía firmas, timbres y membretes que los catalogaban como «urgente», «reservado» o «secreto». Varios llevaban anotaciones manuscritas de las propias autoridades de la época.

Estos materiales permitieron develar una serie de mecanismos globales de acción político represiva del régimen. En especial, comprobar la existencia de una coordinación y flujo de información diario entre las más altas autoridades políticas del régimen y la policía secreta, fuera esta la DINA o la CNI.

Paralelamente, este primer hallazgo permitió inferir la existencia de nuevos documentos reservados y secretos de la dictadura, los que finalmente fueron encontrados en el Archivo Nacional, tras una investigación personal de unos ocho meses en el año 2013.

En total, unas cincuenta mil fojas de oficios fueron revisadas en este nuevo proceso de investigación.

\footnotetext{
En general, los oficios secretos citados constituyen ejemplos de prácticas institucionales habituales. Sería inoficioso referir todos los oficios sobre un tema, en opinión del autor.

Investigación que derivó en el libro de Mauricio Weibel, Asociación llícita, los archivos secretos de la dictadura militar, Santiago de Chile, Ceibo, 2012.
} 
El primer objetivo de este esfuerzo fue seleccionar el corpus sobre el cual debía trabajarse, centrándose en esta etapa en el estudio de documentos referidos a la educación escolar.

El segundo objetivo de este esfuerzo fue establecer una cartografía inicial de los procesos y dispositivos presentes en las decisiones político-represivas del régimen, a través de las coordinaciones entre la Presidencia, la Junta Militar, el Ministerio de Educación y la CNI, la policía secreta.

De hecho, entre 1979 y 1990 -período al que corresponden los archivos secretos analizadosel Ministerio de Educación y la Central Nacional de Informaciones mantuvieron comunicaciones formales y escritas diarias referidas a aspectos como: i) informes de inteligencia, ii) coordinación de planes de guerra interna, iii) coordinación de acciones internacionales y iv) solicitudes de investigación de colegios, estudiantes o profesores, entre otros ámbitos.

Es decir, diversos documentos muestran una colaboración y coordinación permanente y sistemática entre el Ministerio de Educación y la Central Nacional de Informaciones en el despliegue de la política de transformación del sistema educacional, incluso en documentos en que la policía secreta evidencia su preocupación por temas como el lucro o los contenidos del currículum ${ }^{6}$.

«Parece necesario adoptar medidas precisas con el objeto de impedir que organizaciones con intereses personales de lucro o políticos se

Oficio Reservado 211708 del director nacional de la CNI, Humberto Gordon, a la ministra de Educación, Mónica Madariaga, fechado el 18 de agosto de 1983. hagan cargo de corporaciones educacionales, desvirtuando los principios del supremo gobierno", alertó por ejemplo en 1986 el director de la CNI, general Humberto Gordon, en el Oficio Reservado 211708.

Dada la vastedad de los materiales encontrados, esta investigación fue diseñada como un estudio exploratorio.

Es decir, dado que no existen en Chile y/o Latinoamérica otros estudios equivalentes con archivos secretos, el primer esfuerzo fue la identificación de los procesos y dispositivos que constituyeron las prácticas sociales genocidas desplegadas en el proceso de transformación de la educación escolar.

Estos procesos, por cierto, se enmarcan en los tres momentos que operan en el despliegue de las prácticas sociales genocidas.

Es decir, un momento de pre producción que es la construcción de otredades negativas; un momento de producción que implica el exterminio, primero, y la transformación social, después; y un momento de post producción que es el de la validación simbólica de la transformación.

\subsection{Identidad y otredades negativas}

El proceso de construcción social de otredades negativas que caracterizó el período previo al golpe militar del 11 de septiembre de 1973 persistió como una condición indispensable para el despliegue de las prácticas sociales genocidas a lo largo de toda la dictadura.

De acuerdo a los documentos revisados, este proceso de negación del otro operó al menos 
a través de cuatro dispositivos institucionales permanentes en el ámbito escolar: i) seguimiento y exterminio de opositores al régimen militar en el ámbito escolar, ii) selección y exoneración masiva de profesores de acuerdo a antecedentes políticos, iii) formación segregada socialmente de una juventud leal al régimen y iv) fomento del colaboracionismo civil en las comunidades escolares.

En este marco, la construcción de identidad a favor del proyecto neoliberal de educación y la consiguiente articulación de otredades negativas operó sobre la base de la neutralización física y simbólica de opositores, así como de la construcción de una identidad propia.

Materialmente, esto se tradujo en un exterminio de 115 escolares durante la dictadura militar. De ellos, 81 fueron ultimados por agentes del Estado entre 1973 y 1979, previo al inicio de la municipalización (transformación) de la educación escolar. Los restantes 34 lo fueron en la década de 1980. Además, otros 151 menores de 18 años supuestamente no pertenecientes al sistema educacional fueron asesinados en todo el período. En total, 276 menores de 18 años -estudiantes y no estudiantes- fueron eliminados por agentes del Estado en dictadura.

Este exterminio no fue casual o accidental, sino que coincidió con el despliegue permanente de la CNI en los colegios por instrucciones formales de los sucesivos ministros de Educación, quienes ordenaron directamente a la $\mathrm{CNI}$ investigar diferentes comunidades escolares del país, fueran éstas pertenecientes a liceos públicos, colegios particulares, católicos o subvencionados.

Un ejemplo indesmentible de estas prácticas sociales quedó plasmado en el oficio secreto 174 del 29 de abril de 1986. «Solicito a usted verificar los antecedentes de estos jóvenes y tomar las medidas que esa Central estime convenientes», redactó el ministro de Educación, Sergio Gaete en esa ocasión.

Ante estos requerimientos ministeriales, la $\mathrm{CNI}$ elaboró una amplia variedad de informes, incluyendo análisis globales de la comunidad escolar espiada, fichas de los profesores y de los estudiantes, además de recomendaciones administrativas y políticas para la intervención en cada colegio ${ }^{7}$.

Establecimientos como el colegio Andacollo, el colegio Don Bosco, el colegio de los Sagrados Corazones de Alameda, la Alianza Francesa, el liceo A-12 o el colegio Regina Pacis fueron investigados, por ejemplo, en Santiago. Otros lo fueron en regiones ${ }^{8}$.

El objetivo de este espionaje -dirigido directamente desde el despacho ministerial como muestran los oficios secretos ${ }^{9}$ - fue siempre lo que podría llamarse la «normalización», es decir la imposición de una identidad monocultural cercana al ethos de las transformaciones en desarrollo en la educación y la sociedad.

Se trataba de eliminar un pensamiento y una cultura, para poder construir una juventud nueva,

\footnotetext{
Oficio Reservado 210628 del director nacional de la CNI, Odlanier Mena, al Ministro de Educación, Alfredo Prieto, fechado el 27 de mayo de 1980

8 Oficio Reservado 439 del ministro de Educación Pública, Alfredo Prieto, al Ministerio del Interior, fechado el 7 de diciembre de 1981.

9 Uno de los oficios más impactantes es el que envía en 1979 el entonces ministro de Educación Pública, el historiador Gonzalo Vial Correa a Pinochet, pidiéndole que acelere institucionalmente la cooperación entre su ministerio y la Central Nacional de Informaciones, para revisar los antecedentes de noventa mil profesores que laboraban en la educación pública.
} 
nacionalista y leal al régimen, como subraya por ejemplo el general Humberto Gordon, director de la CNI, en sus intercambios con el Ministerio de Educación.

Las investigaciones de la policía secreta en las comunidades escolares fueron motivadas por supuestos proselitismos políticos de parte de estudiantes y/o profesores, porque no fuera cantada la estrofa final de la Canción Nacional o, por disconformidades con el tenor supuestamente político de algunas pruebas que rendían los alumnos, entre otra variedad de razones, expuestas por escrito en los documentos hallados.

En 1983, por ejemplo, el mismo general Gordon envió un oficio secreto al viceministro de Educación, el capitán de fragata Juan Enrique Fröemel Andrade. En dicho documento Gordon detalló en tres páginas mecanografiadas las acciones del estudiante Iván Salinas, denunciado por una profesora. «Es el organizador de las exposiciones de pintura que se realizan en el colegio», apuntó el jefe de la policía.

Estas operaciones, que se inmiscuían en espacios de micropolítica, abren un debate sobre la naturaleza del régimen militar, permitiendo aseverar que éste fue un régimen de intenciones totalitarias, pero que tal condición estuvo limitada por las resistencias sociales y muy en especial por la estrategia de los movimientos estudiantiles de crear espacios de democracia al interior de los espacios ocupados cívico-militarmente, como los propios establecimientos educacionales.

Pero los dispositivos de control son siempre también dispositivos de transformación. Ello está en la base de la naturalización de las propias transformaciones surgidas de prácticas sociales genocidas.

El proceso de espionaje, seguimiento y vigilancia sobre las comunidades escolares fue acompañado por un intento sistemático de crear una juventud leal al régimen, operación que tuvo tanto elementos de segregación como de homogeneización ${ }^{10}$.

Sistemáticamente, el régimen destinó recursos a formar política e ideológicamente a los hijos de los altos funcionarios públicos en temas como Seguridad Nacional o Guerra Interna, entre otros, a través de cursos, jornadas y capacitaciones. Es decir, en las lógicas de la Doctrina de Seguridad Nacional.

Hubo un intento permanente por formar una juventud leal escogiendo a estudiantes de colegios y liceos, los que sin embargo no eran reunidos en idénticos procesos formativos, sino separados por origen social, en otra expresión de la segregación en marcha.

Es importante subrayar que en todas las capacitaciones participaron como expositores el propio general Augusto Pinochet, su esposa, Lucía Hiriart, el líder gremialista Jaime Guzmán y ministros de la época, incluidos los de Educación, como describe el oficio 2000/4 del Ministerio Secretaría General de Gobierno del 30 de junio de 1982, dirigido al Ministerio de Educación, donde se detallan la selección de mil estudiantes para esos fines.

Esta era una operación principal del régimen, en la que participaban directamente sus máximas

Oficio Reservado 74/36 del Ministerio Secretaría General de Gobierno al Ministerio de Educación del 22 de agosto de 1983. 
autoridades y líderes. «Nos llevaron a Padre Hurtado y nos hicieron charlas, en grupos pequeños. Había unos jóvenes que dirigían todo. Era un verdadero adoctrinamiento sobre el gobierno militar y lo que era el gremialismo. La idea era formar gente para el futuro, para lo que vendría después del gobierno militar. Patricio Melero, el dirigente de la UDI, pasaba de mesa en mesa, destacando la figura de Jaime Guzmán», recuerda Juan Sepúlveda, hoy ginecólogo.

Como queda de manifiesto en sus oficios secretos, la idea del régimen era constituir en cada liceo una organización leal, perfectamente adoctrinada. «Dada la estructura administrativa de la educación chilena se podrán formar hasta asociaciones de carácter comunal», planteó una minuta del régimen distribuida entre los organizadores del II Congreso Nacional de Estudiantes Secundarios, titulada «Bases para una nueva organización estudiantil».

Esta estructura, que contaría con todo el apoyo del Estado, debía funcionar bajo un sistema de elecciones indirectas que garantizara «la indispensable despolitización de la organización», cuya acción no obstante tenía que trascender «los muros de cada establecimiento».

Además, esta agrupación secundaria debía articularse como las organizaciones estudiantiles designadas y pro-dictadura que existían en la Universidad de Chile y la Pontificia Universidad Católica. Es decir, la FECECH, liderada en 1982 por el excandidato presidencial Pablo Longueira, y la FEUC, encabezada por el hoy senador Jaime Orpis, respectivamente.

La idea era «no crear disonancias negativas en el estudiante al acceder a la educación superior», garantizando la despolitización de los cuerpos sociales intermedios, como postulaba el gremialismo.

Es decir, el control y la transformación unidos, cómo única forma de poder desplegar la transformación genocida hacia la naturalización.

Otro dispositivo utilizado en la construcción de otredades negativas fue la selección y exoneración masiva de profesores, de acuerdo a antecedentes políticos.

Los oficios secretos del régimen militar muestran que desde 1975 la DINA primero y la $\mathrm{CNI}$ después tuvieron la responsabilidad formal y absoluta de autorizar la contratación de todo funcionario público, incluidos los profesores, por orden directa de Pinochet.

Los propios ministros o subsecretarios de Educación debían solicitar este trámite a la DINA y/o la CNI, para que cualquier escuela o liceo fiscal pudiera incorporar a un docente.

Aún más, los ministros habitualmente solicitaron revisión de antecedentes de profesores ya contratados, ante la sospecha de que no fueran leales al régimen militar.

Esta operación comenzó a gran escala en 1979, bajo el mandato del historiador Gonzalo Vial Correa como ministro de Educación Pública.

«El ministro que suscribe ha dispuesto que, durante el curso del mes de septiembre, a más tardar, y encontrándose ya completo el listado nacional de los profesores encasillados, éste sea revisado íntegramente por la Oficina de Seguridad (del Ministerio) a fin de individualizar a los elementos extremistas», enfatizó Vial en un oficio dirigido al general Pinochet. 
El ministro, advirtiendo que la nómina incluía noventa mil docentes, sugirió a Pinochet que la CNI apoyara más activamente las labores de seguridad del Ministerio de Educación Pública, para que no hubiera más profesores "extremistas" en los liceos.

«Sería muy importante que la CNI hiciera su propia revisión, con sus propios archivos, o se combinara para hacerlo con el Ministerio. Estoy solicitando esta ayuda al director de la CNI (Odlanier Mena), la cual agradeceré sea respaldada por Vuestra Excelencia», demandó Vial.

La operación, que no cesó hasta fines del régimen, fue desplegada con fuerza por el sucesor de Vial en el ministerio, Alfredo Prieto Bafalluy, abogado integrante de la Corte Suprema hasta marzo de 2015.

Hacia enero de 1987, unos ocho mil profesores habían sido exonerados por razones políticas (encubiertas en otros argumentos), según uno de estos oficios secretos que describe la intervención y preocupación directa del general Pinochet en el tema ${ }^{11}$.

La participación de Vial y Prieto en estas operaciones coercitivas, ambos destacados profesionales en la U. Católica y la Corte Suprema, respectivamente, abre una serie de interrogantes sobre el papel de los civiles en el despliegue político de la transformación genocida.

Finalmente, en otro dispositivo de construcción de otredades negativas, el Estado motivó

Memorándum Reservado de la directora de Educación, Paulina Dittborn, al ministro de Educación, Sergio Gaete, fechado el 19 de enero de 1987. permanentemente el colaboracionismo civil. Es decir, la denuncia que profesores o apoderados hicieron de hechos reales o inventados ocurridos al interior de sus comunidades escolares.

Estas delaciones -que urgían por medidas coercitivas- quedaron registradas en las cartas que los colaboracionistas enviaron a las autoridades y que fueron adosadas a los oficios secretos ministeriales y de la $\mathrm{CNI}^{12}$. Listas de estudiantes, de detenidos $\mathrm{O}$ de supuestos militantes de partidos opositores fueron compartidas por la $\mathrm{CNI}$ y los ministerios de Interior y Educación.

Colegios privados, católicos, municipalizados o públicos fueron escenario del soplonaje civil. Docentes afines al gobierno informaron periódicamente de las movilizaciones contra el régimen, sobre todo a partir de las protestas de 1983.

«Todo lo anterior lleva a pensar en la urgente necesidad de revisar los actuales sistemas de control (...) sobre los colegios", escribió ante la avalancha tanto de manifestaciones como de delaciones el general Gordon en un informe secreto del 1 de julio de 1983, dirigido al Ministerio de Educación.

En resumen, la construcción de otredades negativas no fue sólo una expresión de un proceso social, sino también el resultado de políticas represivas permanentes cuyo objetivo fue silenciar la expresión de un sector político en la sociedad, incluso en espacios de micropolítica como las salas de clases.

Oficio Reservado 210.275 del director de la CNI, Humberto Gordon, a la Subsecretaría de Educación del 24 de febrero de 1983. 


\subsection{Estado y políticas con perspectiva de seguridad}

El proceso descrito solo puede ser entendido en su globalidad si se comprende que en el Ministerio de Educación existió una articulación institucional y política con perspectiva monocultural y de seguridad.

Esto se tradujo en coordinaciones permanentes e institucionales con la CNI en temas como i) la acción internacional del Ministerio de Educación, ii) el despliegue de políticas educativas en el espacio nacional, iii) los flujos institucionales diarios de informaciones entre el Ministerio y la $\mathrm{CNI}$, iv) las coordinaciones operativas en el marco del Plan de Guerra Interna, que incluían el despliegue de las "fuerzas" del Ministerio y v) la formación de los funcionarios ministeriales en temas de seguridad, como Poder Naval, Guerra Sicológica o Teología de la Liberación.

El resultado de estas operaciones fue la ocupación institucional cívico militar del sistema de educación escolar, condición que parece indispensable para su propia transformación. La acción internacional del Ministerio de Educación, referida a su participación en Unesco o a la colaboración con países centroamericanos, por ejemplo, debió contar siempre con la opinión de Cancillería, Interior y la CNI, órgano que operaba como otro ministerio (Weibel, 2012).

Dada su resistencia en la sociedad, el despliegue de estas políticas educativas en el espacio nacional requirió siempre de la participación de la CNI, para evitar lo que algunos informes de inteligencia llamaban la «desviación de la conducta», es decir, las expresiones de descontento.
Esto se reflejó en las acciones de espionaje ya descritas y en los análisis de los cuerpos de inteligencia sobre las estrategias y tácticas que debía seguir la transformación en educación.

Informes relevantes en este plano fueron los documentos elaborados por la Oficina de Estudios Sociológicos de la Armada, los que detallaban, entre otros aspectos, la evolución de lo que el régimen denominaba el «activismo intelectual y educacional», además de los procesos de "desviación de la conducta», analizados con gráficos y tablas. Todas estas coordinaciones quedaron reflejadas en los flujos institucionales diarios de informaciones entre el Ministerio y la CNI o la Oficina de Estudios Sociológicos de la Armada ${ }^{13}$.

Estos flujos, contenidos en oficios secretos, incluyeron boletines diarios de inteligencia desde la CNI, actas mensuales de incineración de documentos secretos desde el Ministerio a la $\mathrm{CNI}$, solicitudes de información sobre comunidades escolares desde el Ministerio a la $\mathrm{CNI}$, los informes (fichas de antecedentes) sobre profesores desde la CNI al Ministerio, y los análisis sociológicos y estadísticos de la Oficina de Estudios Sociológicos de la Armada hacia ministerios, Junta de Gobierno y Presidencia.

Otro aspecto fue la coordinación operativa en el marco del Plan de Guerra Interna (Weibel, 2012), la que incluía el despliegue de las «fuerzas» del Ministerio de Educación. Es decir, la transformación de equipos materiales y humanos del ministerio en capacidad operativa militar, capaz de intervenir ante eventuales revueltas o rebeliones populares.

\footnotetext{
También quedaron reflejados en las Actas de Incineración de documentos encontradas sistemáticamente en los oficios reservados.
} 
Es decir, ocupados cívico-militarmente, el Ministerio de Educación y el sistema educacional fueron incorporados incluso operativamente a las lógicas de la Doctrina de Seguridad Nacional y a planes concretos de guerra interna.

Un símbolo de esto fue el hecho de que todos los ministros de Educación compraron pistolas Astra calibre 38 con fondos públicos para su uso personal, además de mantener una brigada de seguridad armada al interior del propio ministerio ${ }^{14}$.

También se mantuvo un listado permanente del personal con instrucción militar, así como las altas y bajas de la institución y los vehículos disponibles para ser utilizados en operaciones de ocupación militar urbana.

Finalmente, una de las operaciones más desconocidas fue la formación y entrenamiento de los funcionarios ministeriales en temas de seguridad.

Cada año, personal de diverso rango fue enviado con fondos públicos a la Academia Nacional de Estudios Políticos Estratégicos (ANEPE) para recibir cursos de seguridad, esenciales para poder ascender en el escalafón del Estado. Estos cursos incluyeron las materias de Poder Naval, Guerra Sicológica, Guerra Nuclear, Marxismo y Doctrina de Seguridad Nacional, entre otros.

El propio aparato administrativo del Estado fue militarizado ideológicamente, como parte del proceso transformador genocida.

Oficio Reservado del Ministro de Educación, Sergio Gaete, a la Guarnición Militar de Santiago, fechado el 28 de abril de 1986.
Es decir, la viabilidad y sostenibilidad de largo plazo de la transformación fue cimentada sobre una reestructuración administrativa del Estado y una formación ideológica de sus cuerpos administrativos, incluidos directores de colegios.

Esa guerra (interna) construyó un nuevo Estado, como plantea Tilly (2000).

\subsection{Vigilancia monocultural y de seguridad de la práctica docente}

Si bien los archivos secretos encontrados no refieren extensamente a los debates sobre el currículum, si reflejan una preocupación permanente por vigilar los contenidos de éste y la acción docente en aula desde una perspectiva monocultural y de seguridad.

Esto quedó reflejado en la preocupación de las autoridades porque el currículum reflejara adecuadamente la visión hegemónica de la transformación en curso.

Esto se tradujo, por ejemplo, en la prohibición de textos de Manuel Rojas o Ariel Dorfman por razones políticas, por valorar revueltas indígenas (Sergio Villalobos) o por utilizar palabras que podían ser mal interpretadas, como el vocablo pueblo.

Con una mirada burocrático totalitaria, los ministros y sus subalternos vigilaron siempre la acción docente en aula, prestando atención política y operativa al colaboracionismo ${ }^{15}$.

Oficio Reservado 174 del Ministro de Educación, Sergio Gaete, a la Dirección Nacional de la CNI, fechado el 29 de abril de 1986. 


\subsection{Contención ofensiva/defensiva de actores autónomos}

Si bien el proceso de transformación (municipalización) de la educación chilena tuvo perfiles autoritarios y totalitarios, hubo espacios de influencia en que prefirió mitigar su acción, por razones políticas.

Uno de ellos fue el de los colegios católicos, debido a consideraciones tanto institucionales como políticas, atravesadas por hechos tan significativos como la compleja relación con la Iglesia católica por el tema de las violaciones a los derechos humanos o los espacios de colaboración surgidos con la visita del papa Juan Pablo II en 1987.

Las investigaciones (espionajes) de la CNI fueron permanentes, pero a diferencia de lo sucedido en establecimientos públicos o municipales, el Ministerio de Educación no pudo disponer medidas directas en los colegios católicos.

Ello convirtió a estos establecimientos en un espacio de resistencia, en cierta forma, al proceso de transformación, el que pretendía expresarse desde el cambio estructural de la administración de la educación hasta los contenidos curriculares y las prácticas pedagógicas.

Quizás esta condición parcialmente protegida de estos colegios obedeció a: i) el peso cultural de la Iglesia católica en Chile, ii) el papel mediador de la Santa Sede en los conflictos limítrofes con Argentina hasta 1985 y iii) la visita de Juan Pablo II a Chile en 1987.

Un debate epistolar interesante sobre este tema lo mantienen la CNI, el Ministerio de Educación y el Obispado de Concepción, en el que se despliegan todos estos aspectos. Es decir, vigilancia operativa, resistencia de la comunidad escolar y limitaciones políticas al despliegue de la transformación genocida impulsada por la dictadura.

Ante los continuos seguimientos y amedrentamientos, el obispo de Concepción, José Manuel Santos, reclamó por la vigilancia sobre los colegios católicos de su diócesis, incluidos asaltos a ellos por civiles no identificados, eufemismo con que los opositores llamaban a los agentes de la CNI esos años.

El régimen, en tanto, criticó permanentemente a Santos por la libertad política que existíaal interior delosestablecimientoscatólicos deConcepción, denunciada reiterada y anónimamente por apoderados colaboracionistas.

«He tomado conocimiento de que en algunos colegios católicos de la VIII Región, se han aprovechado sus recintos y enseñanzas para desarrollar materias ajenas por completo al proceso educativo (...) Lo anterior contraviene los objetivos educativos $y$, aún más, se contrapone a lo prescrito por la Constitución Política», advirtió el ministro Sergio Gaete en un oficio del 15 de julio de 1986.

El obispo Santos, en un tono irónico, defendió ante el ministro el derecho de enseñar con libertad y la posibilidad de que los profesores se organizasen para acudir a huelga, en una carta fechada el 21 de julio de 1986.

Luego el religioso denunció ante el ministro los continuos allanamientos nocturnos de que eran víctimas algunos colegios católicos por civiles no identificados. «Pienso señor ministro que el 
informante que mostró tanto celo para transmitirle una información errada (...) lo podría haber tenido al corriente de estos hechos graves (los allanamientos)», redactó el prelado en su misiva.

Pero más allá de esta disputa particular, es importante consignar que las pretensiones totalitarias del régimen encontraron en este tipo de establecimientos un límite al despliegue de sus transformaciones.

\subsection{Cristalización simbólica y constitucional}

La cristalización simbólica y constitucional de la transformación genocida no siempre ocurre. Mucho menos su posterior naturalización.

En Chile, este proceso surgió entrelazado con la instauración de una nueva Constitución en 1980, cuando despuntaban los procesos de modernización neoliberal. García Linera (2011) plantea que las constituciones son siempre armisticios entre las clases sociales. Sin embargo, en Chile más bien existió una capitulación que permitió el desarrollo de una transformación neoliberal inédita en la historia del país ${ }^{16}$.

La construcción de esa capitulación constitucional fue eso sí un proceso que partió con la instauración de la Constitución de 1980 y concluyó con la imposición de una serie de leyes orgánicas constitucionales a fines de la dictadura. Entre ellas, la propia Ley Orgánica Constitucional de Enseñanza (LOCE) de 1989, cuya gestación aparece también en los documentos analizados, destacando la discusión entre derecho a la educación y libertad de enseñanza.

Oficio Reservado 2134 del ministro de Educación, Juan Antonio Guzmán Molinari, a la Presidencia del 27 de agosto de 1987.
Es importante destacar que la imposición de un nuevo orden constitucional fue acompañada, durante diez años, por procesos de formación (capacitación) ad hoc de los aparatos administrativos en las visiones de la Doctrina de Seguridad Nacional, al igual que los miembros e hijos de la élite gobernante.

Adicionalmente, en 1989, la dictadura y amplios sectores de la oposición acordaron una serie de reformas a la Constitución de 1980, pero sin alterar su esencia neoliberal.

En los hechos, se eliminó la idea instaurada constitucionalmente de que podía haber chilenos sin derechos políticos, debido a su pensamiento político, pero se mantuvo el orden legal que validó el modelo neoliberal.

Hubo, por tanto, un proceso sistemático y financiado fiscalmente de validación ideológica del nuevo orden constitucional, el que fue ampliado y precisado hasta fines de la dictadura militar a través de las leyes orgánicas y la validación de la Constitución en el plebiscito reformatorio de 1989.

En democracia, la cristalización simbólica y constitucional de esta transformación perduró a través de una serie de mecanismos que exceden el ámbito de esta investigación.

En este sentido, y a modo de tesis, lo que advino fue la mutación de los dispositivos de poder dictatoriales, pero adecuados a un nuevo modelo político y coercitivo.

Por ejemplo, la construcción de identidad y otredades negativas devino en la naturalización del modo capitalista de vida y la criminalización de la protesta social. 


\section{Conclusiones}

El hallazgo y revisión de sesenta mil fojas de oficios secretos sobre educación de la dictadura militar de Augusto Pinochet (1973-1990) es un hito en la reconstrucción de los procesos, modelos, modos y dispositivos de las prácticas sociales genocidas que fueron aplicadas en Sudamérica y especialmente en Chile para transformar neoliberalmente las relaciones sociales.

El hecho que estos oficios refieran al sector educacional otorga aún mayor relevancia a este descubrimiento, debido al impacto estructural de la educación en todos los aspectos de la sociedad, en especial los de la cultura, la socialización y la memoria. Es decir, el poder.

Es un material encontrado en las bóvedas del Archivo Nacional que abarca desde 1979 hasta 1989, período en que fue municipalizada y privatizada la educación estatal chilena, en medio de otra serie de transformaciones estructurales paralelas que abarcaron el mercado laboral, la seguridad social, la segregación territorial y la estructura productiva.

Sin embargo, estas transformaciones no pueden ser comprendidas por fuera de los procesos globales de represión a los movimientos sociales y de liberación nacional que estallaron desde la década de 1950 en el mundo, lo que en el Cono Sur se expresó en la constitución del Plan Cóndor, iniciativa de los gobiernos y las policías secretas de Argentina, Bolivia, Brasil, Chile, Uruguay y Paraguay.

Los documentos permiten cuestionar una serie de supuestos sobre los modelos de coerción de losregímenesautoritariosy/ototalitarios, además de ampliar la comprensión de las prácticas sociales genocidas, desde los momentos de despliegue de sus transformaciones hasta los de sus naturalizaciones.

Por cierto, las conclusiones obtenidas están limitadas por el hecho de que estos oficios secretos corresponden a un período y a un país determinado.

Sin embargo, la estandarización de la violencia política y de las prácticas sociales genocidas son procesos de estirpe global desde el siglo $X X$, por lo que las inferencias obtenidas pueden ser utilizadas como categorías o hipótesis de trabajo más universales.

Quizá el hallazgo más relevante de este estudio sea demostrar el uso estratégico de diversas prácticas sociales genocidas en la transformación global de la sociedad chilena.

De hecho, el anhelo de construir esta transformación está en la declaración de principios del propio Plan Cóndor y se reitera además textualmente en los oficios secretos de la dictadura militar chilena.

Es decir, el genocidio, o más precisamente el genocidio como práctica social contra la izquierda chilena y latinoamericana, así como contra amplios sectores sindicales e intelectuales, no constituyó sólo el exterminio físico y cultural de una población específica (el enemigo interno), sino que esencialmente apuntaló la transformación de una sociedad a través de mecanismos sociales e institucionales coercitivos que buscaron construir nuevas relaciones y equilibrios entre sociedad, economía y política. Es decir, la suplantación de una cultura por otra. 
Es importante precisar que no todos los genocidios derivan en transformaciones de las relaciones sociales y de poder. Tampoco todas las transformaciones se consolidan como naturalizaciones. El valor de este estudio radica en la revisión con fuentes primarias, de un proceso históricamente situado donde sí ocurrieron todas esas fases. Es decir, donde la transformación se erigió finalmente como naturalización.

Desde Hobbes a Weber, la coerción es entendida como una dimensión esencial de la acción política del Estado, donde la coerción es la continuación de la política por otros medios. Aún más, en cierta forma, la política desde el Estado no puede existir sin ella.

De hecho, en la ciencia política, se definen teóricamente cuatro modelos coercitivos esenciales: i) el burocrático, ii) el ciego, iii) el escondido y iv) el transparente. Los dos primeros corresponden esencialmente a regímenes totalitarios y autoritarios y los últimos a sistemas democráticos. No obstante, el actual despliegue de operaciones globales de los servicios de inteligencia plantea muchas dudas sobre la permeabilidad de estas clasificaciones.

Asimismo, una de las principales revelaciones es que el desarrollo de una transformación genocida que persista en el tiempo -como la chilena- parece requerir la existencia de un modelo especial de coerción, el que llamaremos el modelo burocrático global.

De hecho, uno de los aspectos más sobresalientes de la dictadura, y cimentado en la Doctrina de Seguridad Nacional, fue que la coerción constituyó un despliegue político permanente de las estructuras del Estado en que los órganos represivos actuaron como coordinadores supraministeriales.

Ergo, la coerción no fue la responsabilidad de una agencia con amplios poderes como la Stasi en la RDA, sino una actividad permanente de todas las estructuras del Estado, las que adoptaron la vigilancia y la represión como aspectos clave del despliegue de sus políticas, planes y programas, en coordinación política y operativa diaria con la DINA y la CNI.

Miles de funcionarios públicos fueron de hecho formados en guerra naval, seguridad interna o poder nuclear, entre otros temas. Parafraseando a Tilly, el Estado hizo la coerción y la coerción hizo al Estado.

Es decir, la práctica social genocida para convertirse en un mecanismo de realización perdurable parece requerir justamente de este despliegue global de la coerción en toda la institucionalidad pública.

En el caso chileno, esta ocupación cívicomilitar del Estado y del espacio público fue acompañado por la creación de un espacio de seguridad internacional, expresado en la constitución del Plan Cóndor en 1975 en Santiago y el despliegue incluso anterior de un Plan de Guerra Externa que abarcó todo el planeta, el que fue coordinado con los ministerios por la DINA y la CNI, en especial el Ministerio de Relaciones Exteriores.

Por cierto, estos hallazgos introducen una serie de interrogantes -algunas inquietantes- sobre los matices en los modelos de coerción desplegados al interior de los países del Plan Cóndor y entre estos países y las dictaduras de otros continentes, como las africanas, asiáticas o europeas. 
Por ejemplo, ¿cuánto influyen la cultura y la historia oficial, en tanto ideología, en la formación de estos modos de coerción? ¿De qué forma los modelos de organización de la coerción influyen además en la profundidad y alcance de las violaciones a los derechos humanos? ¿Es posible plantear una relación entre los modos de coerción y los tipos de salidas democráticas tras ellos?

Por ahora estas interrogantes están abiertas y probablemente las prácticas y las transformaciones sociales genocidas estarán siempre influidas por otra serie de procesos políticos y sociales que complejizan la posibilidad de obtener respuestas unívocas.

La revisión de estos corpus también sometió a litigio y amplió una serie de teorizaciones sobre las propias prácticas sociales genocidas.

Las tesis de Feierstein (2007) advertían que las prácticas sociales genocidas operan en un momento de pre producción que es la construcción de otredades negativas; un momento de producciónque implica el exterminio, primero, y la transformación social, después; y un momento de post producción que es el de la validación simbólica de la transformación.

La revisión de los archivos secretos de la dictadura militar permite observar empíricamente que estos momentos en realidad se entrecruzan y se requieren mutuamente, pero que también están limitados por las acciones de resistencia y memoria. Ese es un aporte esencial.

Por ejemplo, la construcción general de otredades negativas que caracterizó el período previo al golpe militar del 11 de septiembre de 1973 significó una condición indispensable para la realización de las prácticas sociales genocidas desplegadas desde el Estado.

En democracia, donde se mantuvo el modelo heredado de la dictadura, esta otredad negativa persistió como la criminalización de la protesta social y la consolidación de la segregación socioestructural y socioterritorial.

Asimismo, la cristalización simbólica operó desde un inicio a través de la ocupación del espacio público, la censura de medios y artistas y la formación de funcionarios y sectores sociales leales.

En democracia, a través de la naturalización del modo de vida instaurado en dictadura. Del mundo popular a la democracia del consumo.

En términos esquemáticos, los procesos específicos que marcaron la transformación de la educación escolar chilena, como práctica y transformación social genocida, fueron básicamente los siguientes: i) Construcción de identidad y otredades negativas, ii) Articulación de Estado y políticas públicas con perspectiva de seguridad, iii) Vigilancia monocultural y con perspectiva de seguridad de la práctica docente, iv) Contención ofensiva/defensiva de actores autónomos y v) Cristalización simbólica y constitucional de la transformación.

Un aspecto excluido por ahora de este estudio es cómo y por qué la cristalización simbólica y constitucional de la transformación ha logrado sobrevivir por décadas al propio fin del régimen que la instauró, pese a las evidentes segregaciones socioestructurales que generó.

Estudiar a futuro este fenómeno resulta de sumo interés, pues constituye el proceso 
de perpetuación de la transformación, su naturalización. Una tesis inicial de trabajo en esa línea - por cierto, inquietante- es que no solo se naturalizó el modelo económico y político, sino también los modos coercitivos con sus respectivas mutaciones.

La ajenización del otro devino en la criminalización de la acción colectiva y en especial de la protesta social. La vigilancia monocultural derivó en la concentración de medios y discursos, por ejemplo.

Asimismo, la democracia debió desplegarse a través de un Estado de construcción coercitiva, donde la participación ciudadana estaba excluida como eje de acción política. El Estado coercitivo construyó la transición a la democracia.

Por cierto, estos son temas en exploración y litigio, pero que requieren ser abordados para comprender por qué y cómo la transformación de la educación logró perdurar en Chile por décadas, acentuando las transformaciones en las relaciones sociales impulsadas bajo la dictadura.

La dictadura, a diferencia de lo usualmente planteado, fue siempre un régimen de estirpe totalitaria, preocupada por ejemplo del espionaje de decenas de miles de profesores o niños y de toda actividad divergente incluso en espacios de micropolítica como las aulas.

$\mathrm{Si}$ ese totalitarismo no siempre pudo desplegarse, reduciéndose a un autoritarismo, fue porque existió un poderoso movimiento social y especialmente estudiantil que tuvo la lucidez de levantar la construcción de democracia en espacios de micropolítica como su principal estrategia de lucha.
Sin esta acción, la dictadura habría sido inevitablemente un régimen totalitario en el mundo escolar y sus transformaciones mucho más profundas.

Irónicamente, es probable que la transformación genocida logró desplegarse y naturalizarse en la educación secundaria porque estos dispositivos de resistencia se desarticularon socialmente en democracia.

Hay otra serie de disquisiciones e interrogantes pendientes, algunas ya enunciadas. Sin embargo, algunas de las líneas más importantes de una eventual investigación futura debieran estar ligadas a las relaciones entre la transformación genocida y la lucha de clases, la influencia de la cultura en la articulación de los diferentes modelos de coerción, la cristalización ideológica de las prácticas sociales genocidas en los cuerpos coercitivos y la resignificación de los dispositivos genocidas en los regímenes democráticos como condición para que persista la transformación genocida.

También, en un plano más teórico, a las relaciones entre llustración, ajenización del otro y transformación genocida. Todo ello como un problema civilizatorio.

Sin duda es un tema tan apasionante como inquietante que desde el genocidio de los pueblos originarios ha estado en la base de la construcción de la heterogeneidad estructural de América latina y el Caribe.

Por ello, su estudio es esencial para la comprensión de procesos históricos y sociales que han determinado la vida de cientos de millones de personas por décadas tanto en Chile como en América latina y el mundo. 


\section{Bibliografía}

Álvarez, Rolando; 2008. Su revolución contra nuestra revolución, Santiago de Chile, LOM.

Chalk, Frank y Jomassohn, Kurt; 1990; The History and Sociology of Genocide: Analyses and Case Studies; New Haven; Yale Univerisity Press.

Charny, Israel; 2000; Encyclopedia of genocide; California; $A B C-C L I O$.

Dadrian, Vahankn; 2003: The History of the Armenian Genocide: Ethnic Conflict from the Balkans to Anatolia to the Caucasus; New York; Berghahn Books.

Feierstein, Daniel; 2007. El genocidio como práctica social, Buenos Aires, Fondo de Cultura Económica.

García Linera, Álvaro; 2011. Las tensiones creativas de la revolución, La Paz, Vicepresidencia de Bolivia.

Lemkin, Raphael; 1944. Axis Rule in Occupied Europe, Washington, Carnegie Endownment for International Peace.

Policzer, Pablo; 2006. "Human Rights Violation beyond the State", Journal of Human Rights, págs. 215-233.

en Chile, Chile, LOM.

2014. Los modelos del horror. Represión e información Lom.

Salazar, Manuel; 2012. Las letras del horror, Santiago de Chile,

Tilly, Charles (2000) "Historical Analysis of Political Process". En Handbokk of Sociological Theory, editado por Jonathan Turner. Nueva York, Plenum.

Traverso, Enzo; 2001. El totalitarismo, historia de un debate, Buenos Aires, Eudeba.
Weibel, Mauricio; 2012. Asociación llícita, los archivos secretos de la dictadura militar, Santiago, Ceibo.

Weiner, Tim; 2008, Legado de cenizas, la historia de la CIA, Buenos Aires, Random House Mondadori.

\section{Informes $y$ oficios secretos ${ }^{17}$}

Informes secretos de apreciación sociológica de la Armada entre 1982 y 1989, disponibles en el Archivo del Ministerio de Relaciones Exteriores.

Oficios secretos y reservados de la Central Nacional de Informaciones entre 1982 y 1989, disponibles en el Archivo del Ministerio de Relaciones Exteriores.

Oficios, secretos y reservados de la Dirección de Inteligencia Nacional entre 1975 y 1976, disponibles en el Archivo del Ministerio de Relaciones Exteriores.

Oficios, memorandos e informes secretos y reservados de la Junta Militar entre 1973 y 1990, disponibles en el Archivo del Ministerio de Relaciones Exteriores..

Oficios, memorandos e informes secretos y reservados del Ministerio de Educación entre 1973 y 1989, disponibles en el Archivo Nacional.

Oficios, memorandos e informes secretos y reservados del Ministerio de Relaciones Exteriores entre 1973 y 1989, disponibles en el Archivo del Ministerio de Relaciones Exteriores.

Oficios, memorandos e informes secretos, confidenciales y reservados del Ministerio del Interior entre 1973 y 1989 , disponibles en el Archivo Nacional

17 Los oficios secretos, reservados y confidenciales de la dictadura cívico militar chilena (1973-1990) hoy son de libre acceso. Están en el Archivo Nacional, aún sin catalogar, lo que obliga a arduas horas de búsqueda. Los documentos más importantes para este artículo fueron digitalizados y catalogados por la Universidad de la Frontera y están disponibles en su biblioteca digital, en la Colección Mauricio Weibel. Sin embargo, miles de documentos, que no están ligados directamente a esta investigación, y que sirvieron para otros trabajos o libros, están digitalizados y en poder del autor de este artículo, contactable en el correo electrónico weibel.mauricio@gmail.com. 